\title{
Expression and characterization of a human cDNA that complements the temperature-sensitive defect in dolichol kinase activity in the yeast sec59-1 mutant: the enzymatic phosphorylation of dolichol and diacylglycerol are catalyzed by separate CTP-mediated kinase activities in Saccharomyces cerevisiae
}

Fabiana Fernandez ${ }^{2}$, Preetha Shridas ${ }^{3}$, Songmin Jiang ${ }^{3}$, Markus Aebi², and Charles J. Waechter ${ }^{1,3}$

\footnotetext{
${ }^{2}$ Institut fur Mikrobiologie, ETH Zentrum, CH-8092 Zurich, Switzerland, and ${ }^{3}$ Department of Molecular and Cellular Biochemistry, Medical Center, University of Kentucky College of Medicine, Lexington, KY 40536, USA

Received on March 11, 2002; revised on May 1, 2002; accepted on May 21, 2002
}

Dolichol kinase (DK) catalyzes the CTP-mediated phosphorylation of dolichol in eukaryotic cells, the terminal step in dolichyl monophosphate (Dol-P) biosynthesis de novo. In $S$. cerevisiae, the $S E C 59$ gene encodes a protein essential for the expression of $\mathrm{DK}$, an enzyme activity that is required for cell viability and normal rates of lipid intermediate synthesis and protein $\mathrm{N}$-glycosylation. This study identifies a cDNA clone from human brain that encodes the mammalian homolog of DK (hDK1p). $h D K 1$ is capable of complementing the growth defect, elevating DK activity, and consequently increasing Dol-P levels in vivo and restoring normal $\mathrm{N}$-glycosylation of carboxypeptidase $\mathrm{Y}$ at the restrictive temperature in the temperature-sensitive mutant sec59-1. The CTP-mediated phosphorylation of diacylglycerol (DAG) is unaffected by either the temperaturesensitive mutation in the sec59-1 strain, overexpression of the SEC59 gene, or the mammalian homolog $h D K 1$ under conditions that produced a loss or elevation in the level of DK activity. Additionally, overexpression of $\mathrm{hDK} 1 \mathrm{p}$ in $\mathrm{Sf}-9$ cells resulted in a 15-fold increase in DK activity but not DAG kinase activity in crude microsomal fractions. The cloned cDNA contains an open reading frame that would encode a protein with 538 amino acids and a molecular weight of $59,268 \mathrm{kDa}$. Consistent with this prediction, new polypeptides were detected with an apparent molecular weight of 59-60 kDa when $\mathrm{His}_{6}$-tagged constructs of $h D K 1$ or the SEC59 gene were expressed in $\mathrm{Sf}-9$ cells or the temperaturesensitive sec59-1 mutant cells, respectively. These results identify the first cDNA clone encoding a protein required for the expression of DK activity, possibly the catalytic subunit, in a mammalian cell, and establish that the phosphorylation of dolichol and DAG are catalyzed by separate kinase activities in yeast.

\footnotetext{
${ }^{1}$ To whom correspondence should be addressed; E-mail:

waechte@pop.uky.edu
}

Key words: brain/cytosine triphosphate/DNA cloning/dolichol kinase/endoplasmic reticulum

\section{Introduction}

Dolichyl monophosphate (Dol-P) functions as an essential glycosyl carrier lipid in yeast and mammalian cells for the C- (Doucey et al., 1998) and O-mannosylation, N-glycosylation of proteins, and the biosynthesis of glycosyl phosphatidylinositol (GPI) anchors in the endoplasmic reticulum (ER) (Herscovics and Orlean, 1993; Burda and Aebi, 1999). In the current model for de novo biosynthesis, Dol-P is formed in the terminal step by the CTP-mediated phosphorylation of free dolichol catalyzed by dolichol kinase (DK), an enzyme activity detected in microsomal fractions from several mammalian tissues over 20 years ago (Allen et al., 1978; Burton et al., 1979). DK could also play a role in the "recycling" of the glycosyl carrier lipid from Dol-P-P or reserve pools of dolichol (reviewed in Schenk et al., 2001a).

DK is enriched in heavy microsomes from calf brain (Scher et al., 1984) and related studies with liver microsomes indicated that DK has an active site exposed on the cytoplasmic face of the ER (Adair and Cafmeyer, 1983). In vitro studies established that the Dol-P formed via the unusual kinase was accessible to the enzymes synthesizing GlcNAc-P-P-Dol, Man-P-Dol, and Glc-P-Dol in the rough ER (Burton et al., 1979; Spiro and Spiro, 1986; Rosenwald et al., 1990). Although partially purified, delipidated preparations from calf brain microsomes were shown to exhibit a strict requirement for phosphatidylcholine and/or phosphatidylethanolamine for activity (Genain and Waechter, 1990), the mammalian enzyme has not yet been purified.

Szkopinska et al. (1988) reported that when microsomes from yeast were incubated with $\left[\gamma_{-}{ }^{32} \mathrm{P}\right] \mathrm{CTP}$, radiolabeled phosphoryl groups were incorporated into phosphatidate and Dol-P. In Saccharomyces cerevisiae, an essential polypeptide component of DK is encoded by the SEC59 gene, although it not been determined if it is the catalytic subunit (Heller et al., 1992). In the temperature-sensitive yeast mutant sec59-1, DK is defective, and the phenotypic characteristics of the mutant are an inability to phosphorylate dolichol, a lack of Dol-P, and consequently a block in protein $\mathrm{N}$-glycosylation and the essential assembly of GPI anchors. The mutant is unable to grow at the restrictive temperature, but at the permissive temperature, although DK activity is lower than the wild type, it is still sufficient 
to sustain cell growth. However, it has not been previously determined if the phosphorylation of diacylglycerol (DAG) and dolichol are catalyzed by a single or separate CTP-mediated kinases in S. cerevisiae. Moreover, developmental changes in DK activity have been reported for sea urchin embryos (Rossignol et al., 1981), estrogen-treated chick oviducts (Burton et al., 1981); Dictyostelium discoideum (Rossler et al., 1982), and pig (Scher et al., 1985) and rat brain (Volpe et al., 1987; Bhat et al., 1991). However, the molecular tools have not been available to assess whether these changes in activity were due to different levels of expression or modification of the CTP-mediated enzyme.

The experiments in this article describe the first cloning and characterization of a human cDNA that encodes the mammalian homolog of the SEC59 gene from yeast. The cDNA $(h D K 1)$, encoding a component of DK in human brain, is capable of complementing the defects in growth, DK activity and protein $\mathrm{N}$-glycosylation at the restrictive temperature in the sec59-1 mutant cells. Genetic and enzymological evidence is also reported indicating that the CTP-mediated phosphorylation of DAG and dolichol is catalyzed by separate enzymes in S. cerevisiae. The possibility that a component of human DK (hDK1p) is the catalytic subunit of the brain DK is discussed.

\section{Results}

Identification and subcloning of mammalian homolog of SEC59 gene from $\mathrm{S}$. cerevisiae

Ohara and colleagues recently reported the cloning of 100 new cDNAs from human brain libraries (Kikuno et al., 1999). One of these clones (KIAA1094; accession number NM_014908) contains an open reading frame that would encode a protein with more than $30 \%$ identity to the amino acid sequence predicted by the SEC59 gene (accession number NP_013726) from S. cerevisiae (Heller et al., 1992). To investigate the possibility that the KIAA1094 gene encoded the mammalian homolog of SEC59, it was subcloned into the YEp352 vector behind the native SEC59 promoter, and the studies were conducted.

Mammalian cDNA homolog complements the growth and hypoglycosylation of carboxypeptidase Y (CPY) in the sec59-1 mutant at the nonpermissive temperature

As a first approach to determining if the cDNA from human brain, designated KIAA1094, encoded the mammalian homolog of the yeast SEC59 gene, its ability to complement the growth and protein N-glycosylation deficiencies in sec59-1 cells at the nonpermissive temperature was tested. First, as seen in Figure 1, similar rates of growth of all strains were seen at the permissive temperature $\left(23^{\circ} \mathrm{C}\right)$. Though the wild type and other strains were able to grow at the nonpermissive temperature $\left(37^{\circ} \mathrm{C}\right)$, virtually no growth of the sec59-1 mutant transfected with the empty YEp352 vector was observed. However, overexpression of the $h D K 1 \mathrm{cDNA}$, as well as the SEC59 gene, in sec59-1 mutant cells restored normal growth at the nonpermissive temperature $\left(37^{\circ} \mathrm{C}\right)$.

In yeast, the sec59-1 mutation leads to the hypoglycosylation of CPY (vacuolar protein containg four $\mathrm{N}$-linked oligosaccharide chains). A deficit in Dol-P could produce an incomplete glycosylation of glycoproteins due to a deficiency in the level of the

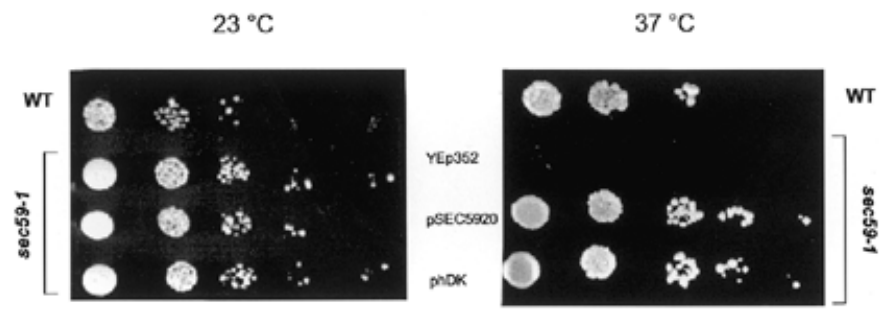

Fig. 1. Overexpression of $h D K 1 \mathrm{cDNA}$ complements the growth phenotype of sec59-1 mutant at the nonpermissive temperature. Serial dilutions of wild type and sec59-1 mutant transformed with different plasmids were plated on YPD media and incubated for 4 days at $23^{\circ} \mathrm{C}$ or $37^{\circ} \mathrm{C}$. The relevant genotypes of the strains are indicated, as well as plasmids used.

lipid-linked oligosaccharide intermediate utilized as substrate by the oligosaccharyltransferase. The reduced glycosylation caused by the sec59-1 mutation in yeast was visualized by the appearance of CPY glycoforms lacking one to four oligosaccharide chains. Consistent with $h D K 1$ being able to restore DK activity and a sufficient supply of Dol-P to maintain lipid intermediate synthesis, overexpression of the $h D K 1$ cDNA also corrected the hypoglycosylation of CPY (Figure 2).

Overexpression of the $h D K 1 \mathrm{cDNA}$ produces an increase in the cellular pool of Dol-P in vivo

The ability of the $h D K 1$ cDNA to complement the growth and hypoglycosylation phenotypes in sec59-1 cells suggested that it could restore kinase activity at the nonpermissive temperature. To obtain corroborative evidence for this conclusion, the levels of dolichol and Dol-P were compared in the mutant before and after transfection with the $h D K 1$ cDNA. The results in Figure 3 (traces A-D) show that all mutant strains have levels of dolichol comparable to the wild-type cells. Three major peaks are seen corresponding to dolichols with chain lengths of 14-16

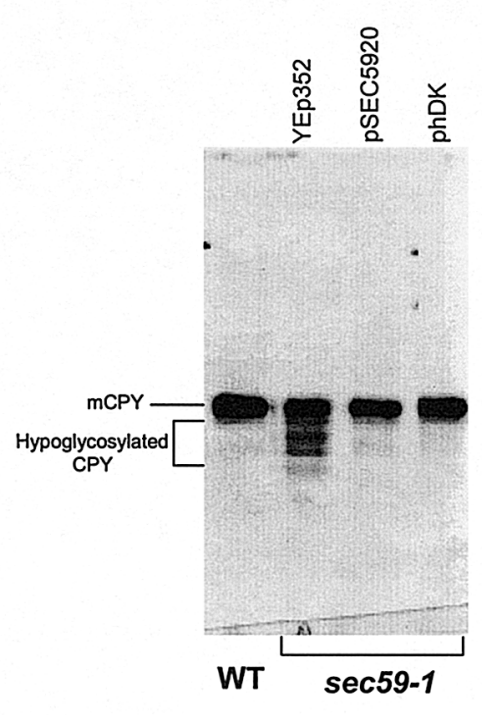

Fig. 2. Overexpression of $h D K 1$ cDNA corrects hypoglycosylation of CPY in sec59-1 mutant at the nonpermissive temperature. Total cell extracts from wild type and sec59-1 mutant were analyzed by SDS-PAGE and immunoblotting using anti-CPY serum. The positions of mature CPY (mCPY) and hypoglycosylated glycoforms lacking one to four $\mathrm{N}$-linked oligosaccharides $(-1$ to -4$)$ are indicated. 
A

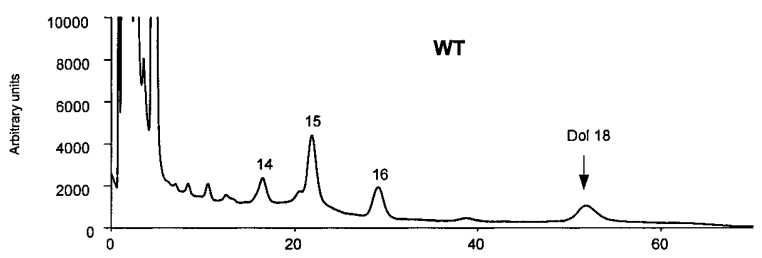

B

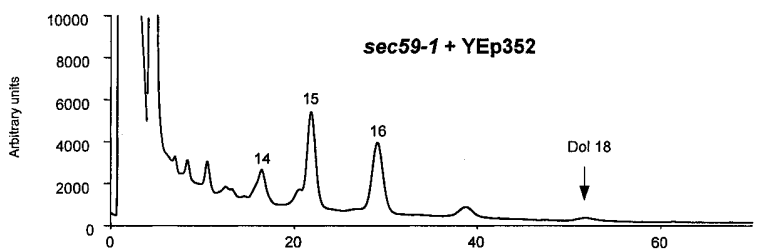

C

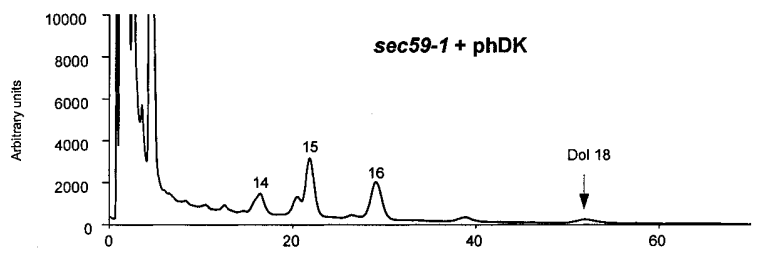

D

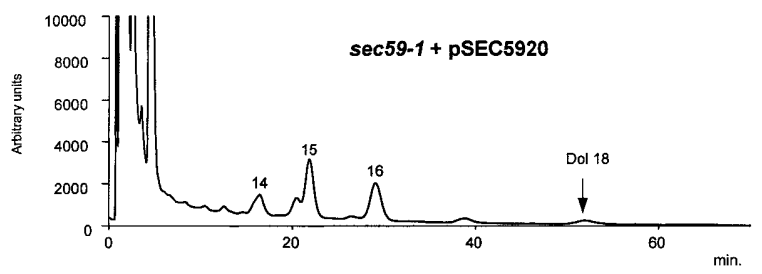

Fig. 3. Dolichol levels are comparable in wild type and sec59-1 mutant at the nonpermissive temperature. Cells were grown at $23^{\circ} \mathrm{C}$ and shifted to $37^{\circ} \mathrm{C}$ for $6 \mathrm{~h}$; lipids were extracted from 1000 OD equivalents of cells. Dolichol was analyzed by the procedures described by Schenk et al. (2001b). (A) Wild-type cells (B) sec59-1 + YEp352; (C) sec59-1 + hDK1; (D) sec59-1 + SEC59. Dolichol (Dol-18) composed of 18 isoprene units was added to the cells prior to extraction and served as qualitative and quantitative marker. The chain length of each isoprenolog is indicated above the respective peaks.

isoprene units. However, when sec59-1 cells were grown at the nonpermissive temperature, the levels of Dol-P were barely detectable and significantly lower than wild-type cells (Figure 4, traces $\mathrm{A}$ and $\mathrm{B}$ ). When the sec59-1 mutant was transformed with $h D K 1$ cDNA, Dol-P levels similar to the mutant transfected with SEC59 were observed (Figure 4, traces C and D). Dol-Ps with 14-16 isoprene units were found with (55)Dol-P being the predominant chain length. This result is consistent with the restoration of normal CPY $\mathrm{N}$-glycosylation seen in Figure 2.

\section{Expression of cDNA encoding hDK1 in Sf-9 cells and yeast}

Previous work has established that SEC59 encodes an essential polypeptide required for DK activity (Heller et al., 1992), but it has not been proven that it is the catalytic subunit. The cDNA encoding a construct of hDK1p, the mammalian homolog, with a C-terminal His $_{6}$-tag was expressed in Sf-9 cells to test the possibility that the polypeptide was catalytically active or at least capable of stimulating endogenous activity. As seen in Figure 5, heterologous expression of this cDNA was confirmed by the appearance of new polypeptides with mobilities
A

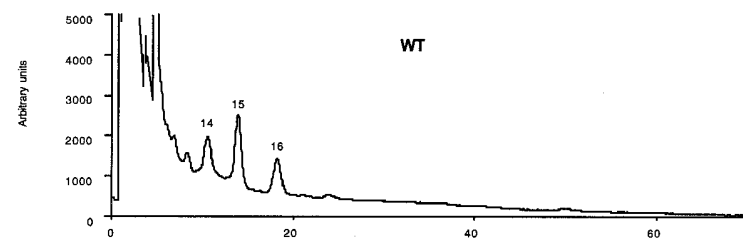

B

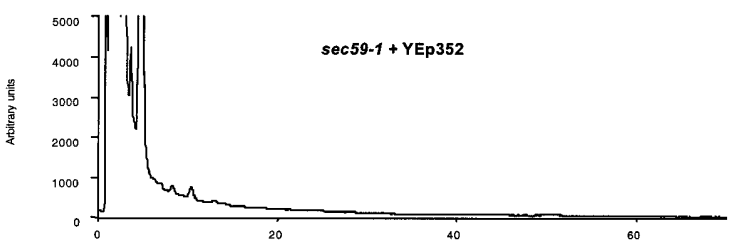

C

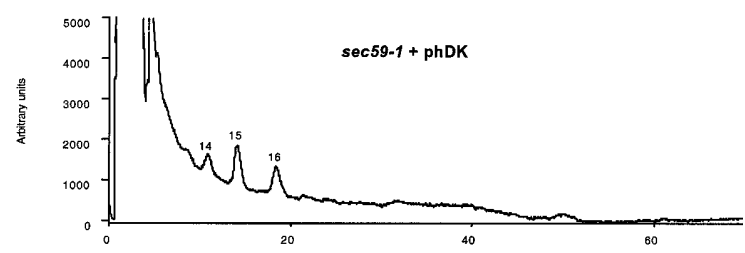

D

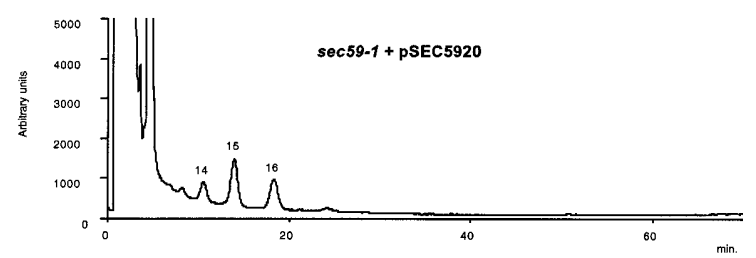

Fig. 4. Dol-P levels are elevated in sec59-1 mutant at the nonpermissive temperature by transfection with $h D K l \mathrm{cDNA}$. Cells were grown at $23^{\circ} \mathrm{C}$ and shifted to $37^{\circ} \mathrm{C}$ for $6 \mathrm{~h}$; lipids were extracted from $1000 \mathrm{OD}$ equivalents of cells. Dol-P-containing fraction was analyzed by the procedures described by Schenk et al. (2001b). (A) Wild-type cells; (B) sec59-1 + YEp 352; (C) sec59-1 $+h D K 1 ;$ (D) sec59-1 + SEC 59. The chain length of each Dol-P isoprenolog is noted above the corresponding peaks.

corresponding to 59-60 kDa in yeast (Figure 5A) and Sf-9 cells (Figure 5B). The polypeptide encoded by $h D K 1$ migrated with the same molecular size as the protein encoded by the SEC59 cDNA in yeast (Figure 5A).

When crude microsomes were prepared from control Sf-9 cells and cells transfected with the His $_{6}$-tagged mammalian homolog $(h D K 1)$, in vitro enzyme assays revealed that expression resulted in a 15-fold increase in DK activity. (Table I I). These results provide good evidence that $h D K 1$, the mammalian homolog of SEC59, encodes either the catalytic subunit of brain DK or an essential regulatory subunit.

\section{CTP-mediated phosphorylation of dolichol and DAG are catalyzed by separate enzymes in $\mathrm{S}$. cerevisiae}

When microsomes from yeast are incubated with $\left[\gamma^{32} \mathrm{P}\right] \mathrm{CTP}$, phosphatidic acid as well as Dol-P are enzymatically labeled (Szkopinska et al., 1988). In this study, in vitro assays were conducted to determine if the SEC59 gene product was essential for the CTP-mediated phosphorylation of dolichol and DAG. As seen in Table II, membranes isolated from the sec59-1 mutant grown at the permissive or nonpermissive temperatures had significantly lower DK activity compared to membranes 
A

B

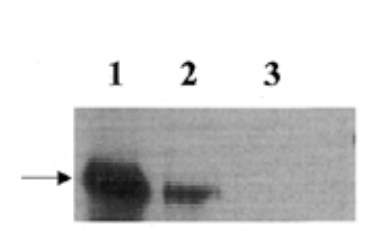

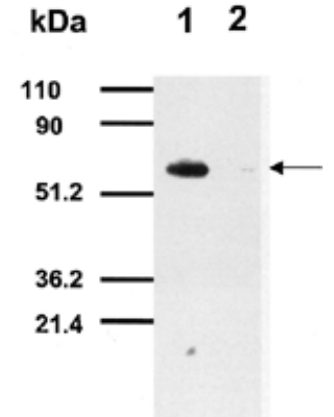

Fig. 5. Expression of $\mathrm{His}_{6}$-tagged constructs of SEC59 and $h D K 1$ cDNA in yeast (A) and $h D K 1$ in Sf-9 cells $(\mathbf{B})$ results in the appearance of new polypeptides migrating with an apparent molecular size of 59-60 $\mathrm{kDa}$ as judged by SDS-PAGE. (A) Lane $1=\sec 59-1$ mutant + pSEC59; lane $2=\sec 59-1$ mutant + phDK1; lane $3=\sec 59-1$ mutant + pYEp352. (B) Lane $1=$ membranes from Sf-9 cells expressing hDK1p; lane $2=$ membranes from untransfected Sf-9 cells. Arrows indicate His ${ }_{6}$-tagged hDK1p expressed in yeast and Sf- 9 cells. SDS-PAGE and detection of $\mathrm{His}_{6}$-tagged proteins were as described in Materials and methods.

Table I. Expression of cDNA encoding hDK1p in Sf-9 cells produces an increase in dolichol kinase activity

\begin{tabular}{lll}
\hline $\begin{array}{l}\text { Membranes from Sf-9 } \\
\text { cells }\end{array}$ & $\begin{array}{l}\text { Exogenous dolichol } \\
(20 \mu \mathrm{g} / 0.1 \mathrm{ml})\end{array}$ & $\begin{array}{l}\text { Dolichol kinase activity } \\
(\mathrm{pmol} / \mathrm{mg} / \mathrm{min})\end{array}$ \\
\hline Untransfected & - & 0.15 \\
Untransfected & + & 0.34 \\
phDK1 & - & 0.18 \\
phDK1 & + & 5.7 \\
\hline
\end{tabular}

Membranes from control and cells transfected with $p h D K 1$ were isolated, and dolichol kinase activity was assayed as described in Materials and methods.

from wild-type cells. Conversely, overexpression of the SEC59 gene resulted in a large increase in DK activity. However, enzymatic phosphorylation of DAG was not affected by either the temperature-sensitive mutation in sec59-1 cells or when the rates of dolichol phosphorylation were increased by overexpression of the SEC59 gene or the cDNA encoding hDK1p. These results provide convincing evidence that the SEC59 gene product is required for expression of DK activity but not DAG kinase activity, raising the possibility that these lipids are phosphorylated by separate CTP-mediated kinases in S. cerevisiae.

Amino acid sequence predicted by $h D K 1$ cDNA and alignment with yeast $D K$ and bacterial CDP-DAG synthases

The cDNA encoding $\mathrm{hDK} 1 \mathrm{p}$ predicts a very hydrophobic protein with 538 amino acids and a molecular weight of 59,268 (Figure 6A). A hydropathy plot based on several algorithms indicate that $\mathrm{hDK} 1 \mathrm{p}$ has 13 transmembrane domains (TMDs) (Figure 6B). Because the $\mathrm{His}_{6}$-tagged construct of hDK1p expressed in Sf-9 and yeast cells have the mobility on sodium dodecyl sulfate-polyacrylamide gel electrophoresis (SDS-PAGE) of polypeptides corresponding to an apparent molecular size of 59-60 kDa (Figure 5). The ER retention signals remain to be
Table II. Effect of temperature-sensitive mutation (sec59-1) and overexpression of the wild-type SEC59 gene and cDNA encoding hDK1p on dolichol kinase and diacylglycerol kinase activity in $S$. cerevisiae

\begin{tabular}{lll}
\hline Source of membranes & $\begin{array}{l}\text { Diacylglycerol kinase } \\
\text { activity }(\mathrm{pmol} / \mathrm{mg} / \mathrm{min})\end{array}$ & $\begin{array}{l}\text { Dolichol kinase activity } \\
(\mathrm{pmol} / \mathrm{mg} / \mathrm{min})\end{array}$ \\
\hline Wild type & 117 & 3.7 \\
sec59-1 & 101 & 0.1 \\
sec59-1 (hDK1 cDNA) & 96 & 1.0 \\
sec59-1 (SEC59) & 108 & 3.0 \\
\hline
\end{tabular}

Membranes were isolated from the various strains and the lipid kinase activities were assayed as described in Materials and methods. All phosphorylation rates reflect initial rates.

determined because it also lacks a C-terminal KKXX motif (Nilsson et al., 1989). Although dolichol is the primary lipid substrate, hDK1p does not contain any sequences closely resembling the proposed dolichol recognition motif, L-FV-XF-X-X-I-P-F-X-F-Y (Albright et al., 1989). The hDK1p sequence also does not contain any of the three motifs proposed to be involved in the CTP-binding site of CDP-DAG synthase from Bacillus subtilis (Park et al., 1997; Weber et al., 1999), but it does have homology with the same enzyme from other bacterial sources (Figure 6C). The conserved ${ }^{471}$ KTXEG motif (Figure 6A, underscored) on the cytosolic loop between TMDs 11 and 12 of $\mathrm{hDK} 1 \mathrm{p}$ is a candidate for a CTP-binding site. The large cytosolic loop with 69 amino acid residues connecting TMD1 and TMD2 is another possible binding site for the cytidine nucleotide substrate.

\section{Discussion}

Dol-P functions as an essential glycosyl carrier lipid in yeast and mammalian cells (Herscovics and Orlean, 1993; Burda and Aebi, 1999; Schenk et al., 2001a). De novo biosynthesis is initiated by the sequential addition of 12-17 isoprene units from isopentenyl pyrophosphate to farnesyl pyrophosphate catalyzed by ER-associated cis-isoprenyltransferases. The elongation stage is a key rate-controlling event in Dol-P synthesis (Crick et al., 1994; Crick and Waechter, 1994; Konrad and Merz, 1996). In the current view of the pathway the long-chain allylic pyrophosphate intermediate is then dephosphorylated, presumably on the cytoplasmic surface of the ER. The enzyme(s) involved in the dephosphorylation process have not yet been identified, although recent studies (Fernandez et al., 2001) have shown that the CWH8 gene in yeast encodes a Dol-P-P phosphatase with a lumenally oriented active site. The lumenal orientation of the active site suggests that this enzyme is probably not involved in the de novo biosynthetic pathway.

If the fully unsaturated, long-chain polyprenyl alcohol is, indeed, the substrate for the reductase responsible for reducing the double bond in the 2-3 position of the $\alpha$-isoprene unit of dolichol (Sagami et al., 1993), DK would catalyze the terminal step in the biosynthetic pathway de novo. The CTP-mediated kinase could also function by "reactivating" extra-ER reserve pools of dolichol and dolichol derived from the recycling of 
A

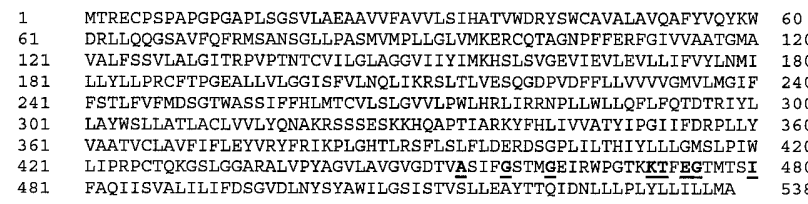

B

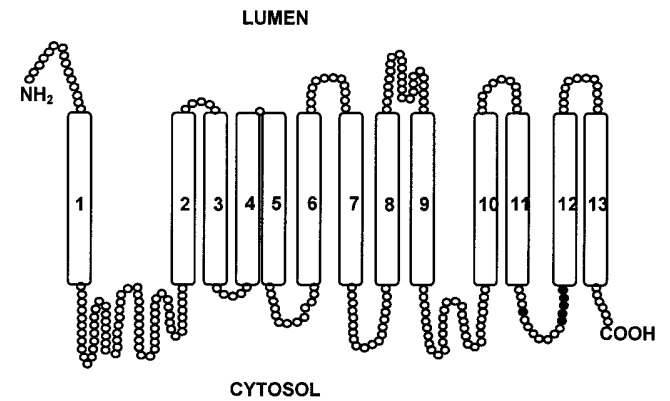

C

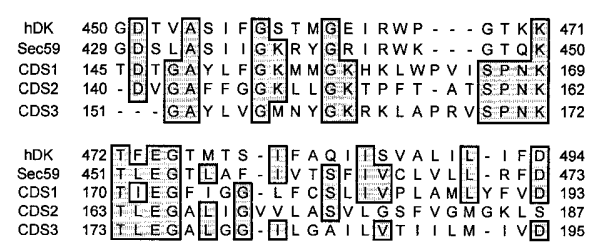

Fig. 6. (A) Deduced amino acid sequence of hDK1p. Residues conserved in hDKp, CDS1, CDS2, and CDS3 are underlined. (B) Hypothetical topological arrangement of $\mathrm{hDK} 1 \mathrm{p}$ in the ER based on the SOSUI system (Mitaku and Hirokawa, 1999). (C) Alignment of sequence of hDK1p (NM_014908) with yeast Sec59p (P20048) and phosphatidate cytidylyltransferase from Staphylococcus aureus (CDS1) (BAB57423), Helicobacter pylori (CDS2) (AAD05785.1), and Streptococcus pneumoniae (CDS3) (NP_344800). Conserved and identical residues are shaded.

Dol-P-P discharged during primary N-glycosylation reactions on the lumenal surface of the ER (reviewed in Schenk et al., 2001a).

Heller et al. (1992) identified the SEC59 gene product as a protein essential for the expression of the yeast enzyme, but the CTP-mediated kinase has not been purified as of this writing. This article identifies a cDNA clone isolated from a human brain library that is proposed to encode the mammalian homolog of the yeast SEC59 gene product. The evidence is based on the observations that the $h D K 1$ cDNA is able to (1) complement the growth phenotype of the sec59-1 mutant at the nonpermissive temperature; (2) correct the hypoglycosylation of CPY due to a reduced level of Dol-P available for the synthesis of lipid intermediates; (3) elevate the levels of cellular Dol-P, presumably as a consequence of restoring DK activity; and (4) produce a 15 -fold increase in DK activity in Sf-9 cells expressing the $h D K 1 \mathrm{cDNA}$. It seems very unlikely that the 15-fold increase is due to hDK1p functioning as regulatory subunit stimulating the Sf-9 enzyme, or that hDK1p, which has 12 TMDs, is a transcription factor. Thus, it is quite possible that $\mathrm{hDK} 1 \mathrm{p}$ is the catalytic subunit of the brain enzyme, although further studies will be required to establish this point conclusively. If $h D K 1$ encodes an accessory or regulatory protein, it is interesting that it is very effective functionally interacting with the yeast and insect enzymes.
The $h D K 1$ cDNA cloned in this study has an open reading frame that encodes a protein with 538 amino acids and a molecular weight of $59,268 \mathrm{kDa}$. The observation that the $\mathrm{His}_{6}$-tagged protein expressed in yeast or $\mathrm{Sf}-9$ cells has the mobility of a 59-60-kDa protein when analyzed by SDS-PAGE suggests that hDK1p may not have a cleavable signal sequence. However, more studies will be required to determine conclusively if the initial translation product of the brain enzyme contains a cleavable signal sequence. Analyses by several hydropathy plots suggest that brain hDK1p is a very hydrophobic protein, with as many as 13 membrane-spanning domains. The conserved ${ }^{471}$ KTXEG motif between TMD11 and TMD12 and a relatively large loop with 69 amino acids exposed on the cytosolic side between TMD1 and TMD2 could be good candidates for the CTP-binding site if $\mathrm{hDK} 1 \mathrm{p}$ is the catalytic subunit of the enzyme. Hydropathy plots of the polypeptides encoded by the $h D K 1 \mathrm{cDNA}$ and the SEC 59 gene predict similarly hydrophobic proteins. In this regard, the prokaryotic counterpart that phosphorylates undecaprenol in bacteria is also apparently extremely hydrophobic and can be solubilized and partially purified in an enzymatically active form in n-butanol (Higashi and Strominger, 1970; Sandermann and Strominger, 1971). It is not surprising that an enzyme that phosphorylates dolichol, the largest aliphatic molecule synthesized in mammalian cells, would contain as many as 13 membrane-spanning $\alpha$-helices. Although the brain enzyme is enriched in heavy microsomes (Scher et al., 1984), it apparently lacks the C-terminal KKXX ER motif (Nilsson et al., 1989). Further studies will be aimed at elucidating the ER retention signals.

It is noteworthy that $\mathrm{hDK} 1 \mathrm{p}$ and Sec59p share homology with several CDP-DAG synthases (Figure 6). However, these sequences do not correspond to the ${ }^{14} \mathrm{HXGH},{ }^{113} \mathrm{RTXGISTT}$, and ${ }^{63} \mathrm{RYVDEVI}$ motifs proposed to form a CTP binding site at the homodimer interface of CDP-DAG synthase from $B$. subtilis by Kent and colleagues (Park et al., 1997; Weber et al., 1999). It is possible that the CTP-binding sites differ because DK catalyzes a $\gamma$-phosphoryl transfer reaction, whereas CDP-DAG synthase is a cytidylyltransferase.

In vitro studies with yeast microsomes previously demonstrated that when yeast microsomes were incubated with $\left[\gamma_{-}{ }^{32} \mathrm{P}\right] \mathrm{CTP}$, radiolabeled phosphoryl groups were transferred into Dol-P and phosphatidic acid (Szkopinska et al., 1988). Although CTP serves as the phosphoryl donor for the enzymatic phosphorylation of dolichol and DAG, it is not the same enzyme catalyzes the phosphorylation of both lipid substrates. The family of DAG kinases is well conserved among most species. There are nine mammalian isotypes (van Blitterswijk and Houssa, 2000); none of these polypeptides has an homolog in $S$. cerevisiae. Thus, it was tempting to speculate that Sec $59 \mathrm{p}$ was responsible for enzymatically phosphorylating DAG.

In addition to providing the first characterization of a mammalian cDNA encoding a protein required for the expression of DK activity, the enzymatic studies reported here indicate that separate CTP-mediated kinases catalyze the phosphorylation of DAG and DK in S. cerevisiae. This conclusion is based on the facts that the temperature-sensitive mutation in Sec59p drastically reduces its ability to phosphorylate dolichol but has no discernible effect on the transfer of ${ }^{32} \mathrm{P}$ from $\left[\gamma^{32} \mathrm{P}\right] \mathrm{CTP}$ to DAG. Similarly, overexpression of Sec59p predictably resulted in elevated levels of DK activity but did not affect the level of 
DAG kinase activity. So far, the CTP-mediated phosphorylation of DAG has not been reported for mammalian cells. It would be interesting to test if Lcb4p and Lcb5p, the sphingosine kinases in S. cerevisiae (Nagiec et al., 1998), which exhibit a low similarity to DAG kinases, are responsible for phosphorylating DAG.

The identification of the brain cDNA encoding a protein required for expression of DK activity should prove to be important for future structure-function and developmental studies on the CTP-mediated kinase. Moreover, several inherited human diseases, congenital disorders of glycosylation (CDGs), have recently been associated with deficiencies in the $\mathrm{N}$-linked glycosylation pathway (Freeze, 2001). Considering that most of the known CDG types affect early steps in this pathway and that availability of Dol-P is one of the rate-controlling factors in the pathway (Harford et al., 1977; Lucas and Levin, 1977; Hubbard and Robbins, 1980; Carson et al., 1981; Spiro and Spiro, 1986; Rosenwald et al., 1990), the hDK1 cDNA described here could provide a valuable probe for potential genetic errors in CDG patients related to defects in DK.

Finally, the structural information obtained from the $h D K 1$ gene may also provide clues to the identity of the genes encoding the CTP-mediated kinases involved in the conversion of farnesol and geranylgeraniol to the respective allylic pyrophosphate intermediates in eukaryotes (Crick et al., 1997; Thai et al., 1999) and the CTP-dependent galactolipid kinase in the chloroplast envelope (Muller et al., 2000). Important goals for future studies will be to determine conclusively if $h D K 1$ encodes the catalytic subunit of the enzyme and if so, to identify the cytoplasmic loops containing the CTP-binding site and reactive center.

\section{Materials and methods}

\section{Materials}

Dolichol was purchased from the collection of polyisoprenols of the Polish Academy of Sciences, Warsaw. Sep-Pak columns were from Waters, Switzerland. All other chemicals and reagents were purchased from standard commercial sources.

\section{Strains and culture conditions}

Escherichia coli strain DH5 $\alpha$ was used for all cloning procedures. $S$. cerevisiae strains used in this study were SS 328 (wild type) is MATa ade2-101 his3D200 lys2-801 ura3-52; YG 0736 is MATa ade2 his3D200 ura3-52 sec59-1; YG 1647 is YG 0736 transformed with plasmid YEp352; YG 1648 is YG 0736 transformed with pSEC59; and YG 1649 is YG 0736 transformed with phDK1. Yeast cells were grown in yeast extract peptone dextrose (YPD) $(1 \% \mathrm{w} / \mathrm{v})$, Bacto yeast extract, $(2 \% \mathrm{w} / \mathrm{v})$, Bactopeptone (Difco Laboratories, Detroit, MI), and 2\% (w/v) glucose) or in yeast nitrogen base without amino acids (Difco) and $2 \%(\mathrm{w} / \mathrm{v})$ glucose supplemented with the appropriate amino acids, purines, and pyrimidines.

\section{Subcloning of KIAA1094 into YEp}

The SEC59 mammalian homolog $(h D K 1)$ was obtained from Dr. N. Kusuhara (Kazusa DNA Research Institute, Kisarazu, Chiba, Japan). The pBluescript II carrying hDK1 was digested with XbaI and XhoI to remove 310 bp (fragment A, bases -317 to -7 ) from the $5^{\prime}$ untranslated region. Primers $\mathrm{ySecP}-\mathrm{Xh} 5$
(ACCGCTCGAGAGATGTATGGGTGTGCG, XhoI site is underscored) and ySec-Xb3 (CTAGTCTAGAATAGGCAATGAACAG, XbaI site is underscored) were used to amplify by polymerase chain reaction (PCR) the $5^{\prime}$ untranslated region of SEC59 gene from $S$. cerevisiae (fragment B, bases -225 to -25 ). Fragment B was digested with $\mathrm{XhoI}$ and $\mathrm{XbaI}$ and ligated into pBluescript to replace fragment A, replacing the human $h D K 1$ promoter with the yeast SEC59 promoter. This construct was excised from pBluescript with XhoI and DraI and ligated to YEp352 previously digested with SalI and SmaI; in this way phDK1 was generated. pSEC59 derivative from YEp352 carrying the yeast SEC59 gene was a gift from Dr. B. Schenk.

\section{Detection of glycoforms of CPY}

Total cell lysates from exponentially growing cells were subjected to 7\% SDS-PAGE and immunoblot analysis with CPY antiserum as described elsewhere (Te Heesen et al., 1992).

\section{Analysis of dolichol and Dol-P}

Cells were grown in YPD at $23^{\circ} \mathrm{C}$ to an $\mathrm{OD}_{600 \mathrm{~nm}}$ of approximately 0.5 and then shifted to $37^{\circ} \mathrm{C}$ for $6 \mathrm{~h}$. Dolichol and Dol-P were extracted and analyzed as described elsewhere (Schenk et al., 2001b).

\section{Recombinant viral expression of mammalian His -tagged $^{- \text {tage }}$ hDK1p in Sf-9 insect cells}

The cDNA containing the entire coding sequence of $h D K 1$ was amplified by PCR using primers 5' AGGTCTAGAGATATGACCCGA $3^{\prime}$ and 5' TCCGGTACCCTAGTGGTGGTGGTGGTGGTGGGCCATCAG 3'. To facilitate the cloning of amplification product, $\mathrm{XbaI}$ and $\mathrm{KpnI}$ sites (underscored) were added at the $5^{\prime}$ end of the primers, respectively. The reverse primer was designed with the sequence for $\mathrm{His}_{6}$-tag. The PCR product was digested with $\mathrm{XbaI} / \mathrm{KpnI}$, ligated into the same restriction enzyme site of pBluescript $\mathrm{KS}(+)$ (Stratagene), and transformed to $E$. coli strain DH5 $\alpha$ cells. The correct sequence of $h D K 1$ gene was confirmed by DNA sequencing. The gene from pBluescript plasmid was subsequently excised and ligated to the same sites of pFASTBAC1 expression vector (Gibco BRL). The recombinant plasmid was then transformed into DH10Bac competent cells, which contain the bacmid with a mini-att $\operatorname{Tn} 7$ target site on the bacmid in the presence of transposition proteins provided by the helper plasmid. The highmolecular-weight DNA prepared from the E. coli clones containing the recombinant bacmid was used to transfect insect cells using CELLFECTIN reagent (Gibco BRL). Sf-9 cells were routinely grown in Sf-900 II serum-free medium containing penicillin/streptomycin at a concentration of $50 \mathrm{U} / \mathrm{ml}$ penicillin and $50 \mu \mathrm{g} / \mathrm{ml}$ streptomycin. Typically, $1-2 \times 10^{7}$ cells of Sf-9 cells were used for transfection with the bacmid for $h D K 1$ expression. The cells were infected with a viral multiplicity of 5-10 and grown in Sf-900 II serum-free medium containing penicillin/streptomycin for $48-72 \mathrm{~h}$.

\section{Construction and expression of $\mathrm{His}_{6}$-tagged Sec59p in yeast}

The SEC59 gene with a C-terminal $\mathrm{His}_{6}$-tag and the $5^{\prime}$ untranslated region of SEC59 gene (bases -225 to -25 ) was amplified by PCR using the primers 5'- ACCGGGATCCAGATGTATGGGTGTGCGG-3' (the BamHI site is underscored), and 5'- TCTAAGCTTTCAGTGGTGGTGGTGGTGGTGAAGAGTAATTAATTT-3' (the HindIII site is underscored) using 
pSEC5920 as template. The PCR product was digested with BamHI and HindIII and ligated to YEp352 plasmid. The resulting plasmid ( $p S E C-H 6)$ was sequenced and then transformed into sec59-1 strains and selected by growing on minimal medium lacking uracil at the restrictive temperature $37^{\circ} \mathrm{C}$.

Preparation of crude microsomal fractions from Sf-9 cells and S. cerevisiae

Infected cells were harvested by centrifugation and suspended in chilled buffer containing $50 \mathrm{mM}$ Tris- $\mathrm{HCl}, \mathrm{pH} 7.4,0.11 \mathrm{M}$ sucrose, $0.5 \mathrm{mM}$ ethylenediamine tetra-acetic acid, and $5 \mathrm{mM}$ 2-mercaptoethanol (buffer A), and disrupted by sonication. The lysate was centrifuged at $2000 \mathrm{rpm}$ for $10 \mathrm{~min}\left(4^{\circ} \mathrm{C}\right)$, and the supernatant centrifuged at $100,000 \times g$ for $20 \mathrm{~min}$ at $4^{\circ} \mathrm{C}$ to sediment crude microsomes. The final pellet was resuspended in buffer A. The protein concentration was determined using BCA protein assay kit (Pierce) with BSA as standard. Yeast cells were grown to an $A_{600}$ of approximately 1.0 and converted to spheroplasts by incubation at $30^{\circ} \mathrm{C}$ in a solution containing $1 \mathrm{M}$ sorbitol, $5 \mathrm{mM} \mathrm{MgCl}_{2}, 10 \mathrm{mM}$ dithiotreitol, $50 \mathrm{mM}$ HEPES, $\mathrm{pH} 7.4$, and $1 \mathrm{mg} / \mathrm{ml}$ Lyticase (Sigma-Aldrich) at a cell density of $200 \mathrm{OD} / \mathrm{ml}$. Following a 30-min incubation, spheroblasts are recovered by sedimentation at 5,000 $\times g$ for $10 \mathrm{~min}$, and the supernatant was poured off. Spheroplasts were lysed by resuspension in 20 volumes of $10 \mathrm{mM}$ HEPES, $\mathrm{pH} 7.4$, $2 \mathrm{mM} \mathrm{MgCl}_{2}, 1 \mathrm{mM}$ phenylmethylsulfonyl fluoride, incubated on ice for $30 \mathrm{~min}$, and homogenized by 12 strokes with a tightfitting dounce homogenizer. The yeast lysate was supplemented with $2 \mathrm{M}$ sucrose to a final sucrose concentration of $0.25 \mathrm{M}$. After removal of unbroken cells and debris by centrifugation at $2500 \times g$, $10 \mathrm{~min}$, yeast microsomes were recovered from the supernatant by sedimentation at $40,000 \times g$ for $20 \mathrm{~min}$. Yeast microsomes were rapidly frozen and stored at $-80^{\circ} \mathrm{C}$ until analysis.

In vitro assay of $D K$ and DAG kinase activity in membrane fractions from $\mathrm{S}$. cerevisiae and $S f-9$ cells

Assay mixtures for Sf-9 cell membranes contained enzyme (1 mg membrane protein), $50 \mathrm{mM}$ Tris- $\mathrm{HCl}$ ( $\mathrm{pH} 7.4), 0.125 \mathrm{M}$ sucrose, $0.5 \mathrm{mM}$ ethylenediamine tetra-acetic acid, $20 \mathrm{mM}$ uridine triphosphate, $16 \mu \mathrm{g}$ dolichol, $30 \mathrm{mM} \mathrm{CaCl}, 5 \mathrm{mM}$ mercaptoethanol, and $40 \mu \mathrm{M}\left[\gamma^{-32} \mathrm{P}\right] \mathrm{CTP}(400 \mathrm{cpm} / \mathrm{pmol})$ in a total volume of $0.1 \mathrm{ml}$. Following incubation for $10 \mathrm{~min}$ at $37^{\circ} \mathrm{C}$, the enzymatic transfer of ${ }^{32} \mathrm{P}$ from $\left[\gamma^{32} \mathrm{P}\right] \mathrm{CTP}$ to Dol-P was assayed essentially by a procedure described elsewhere (Sumbilla and Waechter, 1985). DAG kinase activity in yeast microsomes was assayed by a minor modification using the same incubation conditions. When the crude lipid extracts from enzymatically labeled yeast microsomes were analyzed by thin-layer chromatography on silica gel plates (Baker Si 250), developed with $\mathrm{CHCl}_{3} /$ acetone/ $\mathrm{CH}_{3} \mathrm{OH} /$ acetic acid/ $\mathrm{H}_{2} \mathrm{O}$ (4:3:1:1:0.5), two radioactive products with the mobility of Dol-P and phosphatidate were detected by Bioscan Imaging Scanner System 200-IBM. For routine assays with yeast microsomes the lipid extract was dried and treated with mild base $\left(1.0 \mathrm{ml}\right.$ of $0.1 \mathrm{~N} \mathrm{KOH}$ in $\mathrm{CH}_{3} \mathrm{OH}$-toluene [3:1] for $60 \mathrm{~min}$ at room temperature). Pilot experiments demonstrated that over $99 \%$ of the enzymatically labeled [ $\left.{ }^{32} \mathrm{P}\right] \mathrm{PA}$ was deacylated under these conditions. At the end of the reaction period, the mixture was neutralized by the addition of $0.1 \mathrm{ml}$ of $1 \mathrm{~N}$ acetic acid and a two-phase system produced by the addition of $1.25 \mathrm{ml}$ $\mathrm{CHCl}_{3}$ and $0.35 \mathrm{ml} \mathrm{H}_{2} \mathrm{O}$. Following centrifugation, the upper (aqueous) phase was removed and the lower (organic) phase was washed twice with $0.5 \mathrm{ml}$ of $\mathrm{CHCl}_{3}-\mathrm{CH}_{3} \mathrm{OH}-\mathrm{H}_{2} \mathrm{O}$ $(3: 48: 47)$. The lower phase was transferred to a scintillation vial and dried, and the amount of mild base-stable, labeled Dol-P was determined by scintillation spectrometry. The total amount of radioactivity in the original lipid extract was multiplied by the proportions of the mild base labile (phosphatidate) and mild base-stable product (Dol-P) to calculate the rate of phosphorylation of each phospholipid product.

\section{SDS-PAGE and detection of $\mathrm{His}_{6}$-tagged proteins}

The protein expression was analyzed by $10 \%$ SDS-PAGE (Laemmli, 1970) and detection of $\mathrm{His}_{6}$-tagged fusion protein by western blot analysis using INDIA HisProbe-HRP (Pierce).

\section{Acknowledgments}

We thank Dr. Nobumi Kusuhara (Kazusa DNA Research Institute, Kisarazu, Chiba, Japan) for providing the cDNA designated KIAA1094 and Dr. J.S. Rush for editing the manuscript. This work was supported by NIH grant GM36035 awarded to C.J.W. and grant 31-57082.99 from the Swiss National Science foundation awarded to M.A. F.F. was supported by EU grant QLG1-CT2000-00047 and grant 31-57.082.99 from the Swiss National Science Foundation.

\section{Abbreviations}

CDG, congenital disorder of glycosylation; CPY, carboxypeptidase Y; DAG, diacylglycerol; DK, dolichol kinase; Dol-P, dolichyl monophosphate; ER, endoplasmic reticulum; GPI, glycosylphosphatidylinositol; hDK1p, component of human dolichol kinase; PCR, polymerase chain reaction; SDS-PAGE, sodium dodecyl sulfate-polyacrylamide gel electrophoresis; TMD, transmembrane domain; YPD, yeast extract peptone dextrose.

\section{References}

Adair, W.L. Jr. and Cafmeyer, N. (1983) Topography of dolichyl phosphate synthesis in rat liver microsomes. Transbilayer arrangement of dolichol kinase and long-chain prenyltransferase. Biochim. Biophys. Acta, 751, 21-26.

Albright, C.F., Orlean, P., and Robbins, P.W. (1989) A 13-amino acid peptide in three yeast glycosyltransferases may be involved in dolichol recognition. Proc. Natl Acad. Sci. USA, 86, 7366-7369.

Allen, C.M. Jr., Kalin, J.R., Sack, J., and Verizzo, D. (1978) CTP-dependent dolichol phosphorylation by mammalian cell homogenates. Biochemistry, 17, 5020-5026.

Bhat, N.R., Frank, D.W., Wolf, M.J., and Waechter, C.J. (1991) Developmental changes in enzymes involved in dolichyl phosphate metabolism in cultured embryonic rat brain cells. J. Neurochem., 56, 339-344.

Burda, P. and Aebi, M. (1999) The dolichol pathway of N-linked glycosylation. Biochim. Biophys. Acta, 1426, 239-257.

Burton, W.A., Lucas, J.J., and Waechter, C.J. (1981) Enhanced chick oviduct dolichol kinase activity during estrogen-induced differentiation. J. Biol. Chem., 256, 632-635.

Burton, W.A., Scher, M.G., and Waechter, C.J. (1979) Enzymatic phosphorylation of dolichol in central nervous tissue. J. Biol. Chem., 254, 7129-7136.

Carson, D.D., Earles, B.J., and Lennarz, W.J. (1981) Enhancement of protein glycosylation in tissue slices by dolichylphosphate. J. Biol. Chem., 256, 11552-11557.

Crick, D.C. and Waechter, C.J. (1994) Long-chain cis-isoprenyltransferase activity is induced early in the developmental program for protein $\mathrm{N}$-glycosylation in embryonic rat brain cells. J. Neurochem., 62, 247-256. 
Crick, D.C., Scocca, J.R., Rush, J.S., Frank, D.W., Krag, S.S., and Waechter, C.J. (1994) Induction of dolichyl-saccharide intermediate biosynthesis corresponds to increased long chain cis-isoprenyltransferase activity during the mitogenic response in mouse B cells. J. Biol. Chem., 269, 10559-10565.

Crick, D.C., Andres, D.A., and Waechter, C.J. (1997) Novel salvage pathway utilizing farnesol and geranylgeraniol for protein isoprenylation. Biochem. Biophys. Res. Commun., 237, 483-487.

Doucey, M.A., Hess, D., Cacan, R., and Hofsteenge, J. (1998) Protein C- mannosylation is enzyme -catalysed and uses dolichol-phosphate-mannose as a precursor. Mol. Biol. Cell, 9, 291-300.

Fernandez, F., Rush, J.S., Toke, D.A., Han, G-S., Quinn, J.E., Carman, G.M., Choi, J-Y., Voelker, D.R., Aebi, M., and Waechter, C.J. (2001) The cwh8 gene encodes a dolichyl pyrophosphate phosphatase with a luminally oriented active site in the endoplasmic reticulum of Saccharomyces cerevisiae. J. Biol. Chem., 276, 41455-41464.

Freeze, H. (2001) Update and perspectives on congenital disorders of glycosylation. Glycobiology, 11, 129R-143R.

Genain, C.P. and Waechter, C.J. (1990) Separation of brain dolichol kinase from endogenous activating factors: evidence that phospholipid enhances the interaction between enzyme and dolichol. J. Neurochem., 54, 855-862.

Harford, J.B., Waechter, C.J., and Earl, F.L. (1977) Effect of exogenous dolichyl monophosphate on a developmental change in mannosylphosphoryldolichol biosynthesis. Biochem. Biophys. Res. Commun., 76, 1036-1043.

Heller, L., Orlean, P., and Adair, W.L. Jr. (1992) Saccharomyces cerevisiae sec59-1 cells are deficient in dolichol kinase activity. Proc. Natl Acad. Sci. USA, 89, 7013-7016.

Herscovics, A. and Orlean, P. (1993) Glycoprotein biosynthesis in yeast. FASEB J., 7, 540-550.

Higashi, Y. and Strominger, J. L. (1970) Biosynthesis of peptidoglycan of bacterial cell walls. XX. identification of phosphatidylglycerol and cardiolipin as cofactors for isoprenoid alcohol phosphokinase. J. Biol. Chem., 245, 3691-3696.

Hubbard, S.C. and Robbins, P.W. (1980) Synthesis of the N-linked oligosaccharides of glycoproteins. Assembly of the lipid-linked precursor oligosaccharide and its relation to protein synthesis in vivo. J. Biol. Chem., 255, 11782-11793.

Kikuno, R., Nagase, T., Ishikawa, K., Hirosawa, M., Miyajima, N., Tanaka, A., Kotani, H., Nomura, N., and Ohara, O. (1999) Prediction of the coding sequences of unidentified human genes. XIV. The complete sequences of 100 new cDNA clones from brain which code for large proteins in vitro. DNA Res., 6, 197-205.

Konrad, M. and Merz, W.E. (1996) Long-term effect of cyclic AMP on $\mathrm{N}$-glycosylation is caused by an increase in the activity of the cis-prenyltransferase. Biochem. J., 316, 575-581.

Laemmli, U.K. (1970) Cleavage of structural proteins during the assembly of the head of bacteriophage T4. Nature, 227, 680-685.

Lucas, J.J. and Levin, E. (1977) Increase in the lipid intermediate pathway of protein glycosylation during hen oviduct differentiation. J. Biol. Chem., 252, 4330-4336.

Mitaku, S. and Hirokawa, T. (1999) Physicochemical factors for helical segments and protein-length. Protein Eng., 12, 953-957.

Muller, M.-O., Meylan-Bettex, M., Eckstein, F., Martinoia, E., Siegenthaler, P.-A., and Bovet, L. (2000) Lipid phosphorylation in chloroplast envelopes: evidence for galactolipid CTP-dependent kinase activities. J. Biol. Chem., 275, 19475-19481.

Nagiec, M., Skrzypek, M., Nagiec, E., Lester, R., and Dickson R., (1998) The LCB4 (YOR171c) and LCB5 (YLR260w) genes of Saccharomyces encode sphingoid long chain base kinases. J. Biol. Chem., 273, 19437-19442.
Nilsson, T., Jackson, M., and Peterson, P. (1989) Short cytoplasmic sequences serve as retention signals for transmembrane proteins in the endoplasmic reticulum. Cell, 58, 707-718.

Park, Y.-S., Gee, P., Sanker, S., Schurter, E.J., Zuiderweg, E.R.P., and Kent, C. (1997) Identification of functional conserved residues of CTP:glycerol3-phosphate cytidylyltransferase: role of histidine in the conserved HGXH in catalysis. J. Biol. Chem., 272, 15161-15166.

Rosenwald, A.G., Stoll, J., and Krag, S.S. (1990) Regulation of glycosylation. Three enzymes compete for a common pool of dolichyl phosphate in vivo. J. Biol. Chem., 265, 14544-14553.

Rossignol, D.P., Lennarz, W.J., and Waechter, C.J. (1981) Induction of phosphorylation of dolichol during embryonic development of the sea urchin. J. Biol. Chem., 256, 10538-10542.

Rossler, H.H., Zimpfer, A., and Risse, H-J. (1982) A differentiation-dependent polyisoprenol kinase in Dictyostelium discoideum. Mol. Cell Biochem., 48, 183-189.

Sagami, H., Kurisaki, A., and Ogura, K. (1993) Formation of dolichol from dehydrodolichol is catalyzed by NADPH-dependent reductase localized in microsomes of rat liver. J. Biol. Chem., 268, 10109-10113.

Sandermann, H. Jr. and Strominger, J.L. (1971) C 55 -isoprenoid alcohol phosphokinase: an extremely hydrophobic protein from the bacterial membrane. Proc. Natl Acad. Sci. USA, 68, 2441-2443.

Schenk, B., Fernandez, F., and Waechter, C.J. (2001a) The ins(ide) and outs(ide) of dolichyl phosphate biosynthesis and recycling in the endoplasmic reticulum. Glycobiology, 11, 61R-70R.

Schenk, B., Rush, J.S., Waechter, C.J., and Aebi, M. (2001b) An alternative cis- isoprenyltransferase activity in yeast that produces polyisoprenols with chain length similar to mammalian dolichols. Glycobiology, 11, 1-10.

Scher, M.G., Devries, G.H., and Waechter, C.J. (1984) Subcellular sites of enzymes catalyzing the phosphorylation-dephosphorylation of dolichol in the central nervous system. Arch. Biochem. Biophys., 231, 293-302.

Scher, M.G., Sumbilla, C.M., and Waechter, C.J. (1985) Dolichyl phosphate metabolism in brain. Developmental increase in polyisoprenyl phosphate phosphatase activity. J. Biol. Chem., 260, 13742-13746.

Spiro, M.J. and Spiro, R.G. (1986) Control of N-linked carbohydrate unit synthesis in thyroid endoplasmic reticulum by membrane organization and dolichyl phosphate availability. J. Biol. Chem., 261, 14725-14732.

Sumbilla, C. and Waechter, C.J. (1985) Dolichol kinase, phosphatase, and esterase. Methods Enzymol., 111, 471-482.

Szkopinska, A., Leszek, N., Swiezewska, E., and Palamarczyk, G. (1988) CTP-dependent kinases in yeast. Arch. Biochem. Biophys., 266, 124-131.

Te Heesen, S., Janetzky, B., Lehle, L., and Aebi, M. (1992) The yeast WBP1 is essential for oligosaccharyl transferase activity in vivo and in vitro. EMBO J., 11, 2071-2075.

Thai, L., Rush, J.S., Maul, J. Rodgers, D.L., Chappell, J., and Waechter, C.J. (1999) Farnesol is utilized for isoprenoid biosynthesis in plant cells via farnesyl pyrophosphate formed by successive monophosphorylation reactions. Proc. Natl Acad. Sci. USA, 96, 13080-13085.

van Blitterswijk, W.J. and Houssa, B. (2000) Properties and functions of diacylglycerol kinases. Cell. Signal., 12, 595-605.

Volpe, J.J., Sakakihara, Y., and Rust, R.S. (1987) Dolichol kinase and the regulation of dolichyl phosphate levels in developing brain. Dev. Brain Res., 31, 193-200.

Weber, C.H., Park, Y.-S., Sanker, S., Kent, C., and Ludwig, M.L. (1999) A protoypical cytidylyltransferase: CTP:glycerol-3-phosphate cytidylyltransferase from Bacillus subtilis. Structure, 7, 1113-1124. 